University of Nebraska - Lincoln

DigitalCommons@University of Nebraska - Lincoln

Faculty Papers and Publications in Animal

Science

Animal Science Department

March 1994

\title{
Prediction Error Variances for Interbreed Genetic Evaluations
}

L. Dale Van Vleck

University of Nebraska-Lincoln, dvan-vleck1@unl.edu

Larry V. Cundiff

University of Nebraska-Lincoln, Icundiff2@unl.edu

Follow this and additional works at: https://digitalcommons.unl.edu/animalscifacpub

Part of the Animal Sciences Commons

Van Vleck, L. Dale and Cundiff, Larry V., "Prediction Error Variances for Interbreed Genetic Evaluations" (1994). Faculty Papers and Publications in Animal Science. 255.

https://digitalcommons.unl.edu/animalscifacpub/255

This Article is brought to you for free and open access by the Animal Science Department at DigitalCommons@University of Nebraska - Lincoln. It has been accepted for inclusion in Faculty Papers and Publications in Animal Science by an authorized administrator of DigitalCommons@University of Nebraska - Lincoln. 


\title{
Prediction Error Variances for Interbreed Genetic Evaluations ${ }^{1}$
}

\author{
L. D. Van Vleck* and L. V. Cundiff ${ }^{\dagger}$ \\ Roman L. Hruska U.S. Meat Animal Research Center, ARS, USDA, \\ *Lincoln, NE 68583-0908 and †Clay Center, NE 68933-0166
}

\begin{abstract}
A table for adjusting expected progeny differences (EPD) to a base year and breed basis depends on analyses of records of progeny of bulls of different breeds in a common environment and requires that those reference bulls also have other progeny to provide within-breed EPD. Currently, the germ plasm evaluation project at the Meat Animal Research Center (MARC) provides such a common environment for reference bulls of several breeds for estimation of breed differences for the reference sires. Reference sire estimates of breed differences are adjusted by the difference between average EPD of reference bulls and average EPD for the base year for that breed. Two related questions are as follows: 1) What are confidence ranges for the adjustments and 2) What are accuracies of interbreed EPD? Application of statistical principles and algebra shows that 1) apparent confidence ranges for breed adjustments are small, 2) apparent confidence ranges are substantially underestimated when random sire effects within breed
\end{abstract}

are ignored, 3) correct confidence ranges also are small, 4) usual measures of accuracy cannot be applied to interbreed comparisons, and 5) standard errors of prediction used in calculating confidence ranges for interbreed comparisons are much less affected by variance of the adjustment factors than by within-breed accuracies for two bulls being compared except for bulls with accuracies of near unity. Alternatives of predicting differences between bulls of the same or different breeds or between a bull of any breed and an average bull of a base breed are discussed in terms of confidence ranges. Although most theoretically correct, a major educational effort would be required to explain confidence ranges on expected differences in progeny of two bulls of different breeds. Confidence ranges on expected difference in progeny of a bull and an average bull of a base breed for a base year can be explained with only a slight extension of principles currently taught.

Key Words: Accuracy, Progeny, Predicted Difference, Breed Differences, Beef Cattle

J. Anim. Sci. 1994. 72:1971-1977

\section{Introduction}

Notter (1989) and Notter and Cundiff (1991) developed a method to compare expected progeny differences ( EPD) of bulls of different breeds using the within-breed EPD and estimates of breed differences obtained from analysis of records of progeny in a common environment such as the germ plasm evaluation (GPE) project at the U.S. Meat Animal Research Center (MARC). Animals with records included in the MARC analysis were progeny of bulls that had within-breed evaluations provided by the breed associations. The MARC records are not included in evaluations of the breed associations. The estimates of breed differences from the MARC analysis are adjusted for genetic trend to a common year basis for all

\footnotetext{
${ }^{1}$ Published as paper no. 10486, Journal Ser., Nebraska Agric. Res. Div., Univ. of Nebraska, Lincoln.

Received September 1, 1993.

Accepted March 3, 1994.
}

breeds essentially by adding the difference between average EPD of bulls at MARC and the average EPD of the same breed for the base year. Núnez-Dominguez et al. (1993) updated the estimates of breed differences. The Beef Improvement Federation publishes an updated table of breed differences each year (NúñezDominguez et al., 1992; Cundiff, 1993).

In general, this method requires that bulls of different breeds (reference bulls) have progeny in a common environment (MARC is an example) and those reference bulls also have progeny in national evaluations to provide EPD. The MARC analyses will be used as an example but the methods can be extended to any system with reference sires with progeny in one or more common environments. For ease of discussion, MARC bulls will represent the more general idea of reference bulls in common environments.

The adjustment of interbreed EPD to a common base year seems to be accepted. One question is what measure of accuracy should be attached to an interbreed EPD. Breed EPD are published with a specially 
defined accuracy. An option would be to obtain confidence ranges about the published within-breed EPD that depend on the standard error of prediction, a function of accuracy. The purpose of this research is to examine alternative ways of describing reliability of interbreed EPD.

\section{Methods}

The Notter and Cundiff (1991) equation to adjust the sire breed solution from the reference bull analyses of MARC data for genetic trend to a common base year (e.g., 1990) for breed $i$ is as follows:

$$
\mathbf{M}_{\mathrm{i}}=\mathbf{L}_{\mathbf{i}}+\mathrm{w}_{\mathrm{i}}\left(\mathrm{E}_{\mathrm{i}}-\mathbf{P}_{\mathrm{i}}\right),
$$

where $\mathrm{M}_{\mathrm{i}}=$ the solution for sire breed $\mathrm{i}$ adjusted for genetic trend, $\mathrm{L}_{\mathrm{i}}=$ the solution for sire breed $\mathrm{i}$ from least squares analysis of MARC records of crossbred calves, $E_{i}=$ the mean EPD computed by the $i^{\text {th }}$ breed association for all animals born in the common base year, $\mathrm{P}_{i}=$ the weighted mean EPD of MARC bulls based on non-MARC records as computed by the $i^{\text {th }}$ breed association, and $w_{i}=$ the regression of progeny performance at MARC on the EPD of the sire reported by breed $i$. The theoretical expectation is that $w_{i}=1$. Estimates for $\mathrm{w}_{\mathrm{i}}$ are near 1 for birth weight and weaning weight but are larger for yearling weight (Notter and Cundiff, 1991; Núñez-Dominguez et al., 1993). For this discussion $w_{i}$ is assumed to be unity without error for all breeds.

The estimated transmitting ability adjusted to a common base year for bull $k$ of breed $i$ is as follows:

$$
\hat{\mathrm{u}}_{\mathrm{ik}}=\mathrm{M}_{\mathrm{i}}+\mathrm{EPD}_{\mathrm{ik}}-\mathrm{E}_{\mathrm{i}}
$$

where $\mathrm{EPD}_{\mathrm{ik}}=$ the EPD calculated by the $i^{\text {th }}$ breed association in the same evaluation in which the EPD averaged into $E_{i}$, the mean EPD for the base year, were calculated.

$$
\text { For } \begin{aligned}
\mathbf{w}_{\mathrm{i}}= & 1, \hat{\mathbf{u}}_{\mathrm{ik}}=\left(\mathrm{L}_{\mathrm{i}}+\mathrm{E}_{\mathrm{i}}-\mathrm{P}_{\mathrm{i}}\right)+\mathrm{EPD}_{\mathrm{ik}}-\mathrm{E}_{\mathrm{i}} \\
& =\mathrm{L}_{\mathrm{i}}-\mathrm{P}_{\mathrm{i}}+\mathrm{EPD}_{\mathrm{ik}} .
\end{aligned}
$$

Thus, for $w_{i}=1$, the constant for all bulls of breed $i$ is $L_{i}-P_{i}$, which does not depend on $E_{j}$.

A basic principle for genetic evaluation is that only differences between animals can be predicted. The predicted difference in progeny of bull ik of breed $i$ and bull $\mathrm{jl}$ of breed $\mathrm{j}$ is as follows:

$$
\begin{aligned}
\hat{u}_{i k}-\hat{u}_{j l} & =\left(L_{i}-P_{i}+E P D_{i k}\right)-\left(L_{j}-P_{j}+E P D_{j l}\right) \\
& =\left(L_{i}-L_{j}\right)-\left(P_{i}-P_{j}\right)+E P D_{i k}-E P D_{j 1}
\end{aligned}
$$

A breed table of constants constructed as $B_{i j}=\left(L_{i}-\right.$ $\left.L_{j}\right)-\left(P_{i}-P_{j}\right)$ can be used with the breed association evaluations, $E P D_{i k}$ and $E P D_{j l}$, to predict differences in progeny performance due to additive genetic merit of bulls of breeds $i$ and $j$.

An alternative approach is to construct a breed column by comparing all breeds to the constant for a base breed (for example, breed $B$ ), $L_{B}-P_{B}$ (i.e., $A_{i}=$ $\left.\mathrm{B}_{\mathrm{iB}}=\left[\mathrm{L}_{\mathrm{i}}-\mathrm{L}_{\mathrm{B}}\right]-\left[\mathrm{P}_{\mathrm{i}}-\mathrm{P}_{\mathrm{B}}\right]\right)$. Then the expected transmitting ability of a bull $\mathrm{k}$ of breed i relative to an average bull of breed $B$ born in the base year is $\hat{u}_{\mathrm{ik}}=$ $\mathrm{A}_{\mathrm{i}}+\mathrm{EPD}_{\mathrm{ik}}$. A potential problem with this alternative concerns calculation of prediction error variances for some animals with an evaluation that contains a constant $A_{i}$ and for other animals of the base breed for which the constant $A_{B}=0$. Because with either alternative estimated fixed effects of breeds are included in the adjustment for breed differences, calculation of something equivalent to the usual definition of accuracy (i.e., the correlation between predicted and true transmitting ability) does not seem very meaningful. Therefore, standard errors of prediction (square root of prediction error variance) for the two alternatives will be considered.

Assumptions will be that 1) sire and residual components of variance are the same for all breeds, although the extension to heterogeneous variances is obvious, 2) accuracy values reported by breed associations can be converted to the traditional definition of accuracy, 3) $\mathrm{w}_{\mathrm{i}}=1$ for all breeds, and 4) adjustments for fixed effects other than sire breed effects are perfect or are not needed in the model of analysis for approximation of $V\left(B_{i j}\right)$. Testing the validity of these assumptions will be difficult and will not be attempted here. The variance of prediction error for differences in performance of progeny of bulls $i k$ and $j l$ is as follows:

$$
V\left[\left(\hat{u}_{i k}-\hat{u}_{j}\right)-\left(u_{i k}-u_{j}\right)\right]
$$

where $u_{i k}$ and $u_{j l}$ are true transmitting values as deviations from breed effects. In terms of $B_{i j}, E D_{i k}$ and $\mathrm{EPD}_{\mathrm{jl}}$, prediction error variance is as follows:

$$
\mathrm{V}\left[\mathrm{B}_{\mathrm{ij}}+\left(\mathrm{EPD} \mathrm{D}_{\mathrm{ik}}-\mathrm{PD}_{\mathrm{ik}}\right)-\left(\mathrm{EPD}_{\mathrm{j} 1}-\mathrm{PD}_{\mathrm{jl}}\right)\right]
$$

From basic principles:

$$
\mathrm{V}\left(\mathrm{EPD}_{\mathrm{ik}}-\mathrm{PD}_{\mathrm{ik}}\right)=\left(1-\mathrm{r}_{\mathrm{ik}}^{2}\right) \sigma_{\mathrm{s}}^{2}
$$

where $r_{i k}^{2}=$ the square of the correlation (traditional definition of accuracy) between true and predicted progeny performance for bull ik as a deviation from a constant for breed $i$ and $\sigma_{\mathrm{s}}^{2}$ is the sire component of variance (one-fourth additive genetic variance) for the trait. Because $E P D_{i k}$ and $E P D_{j l}$ are from independent evaluations by the breed associations for breeds $i$ and $j, \operatorname{COV}\left[\left(E P D_{i k}-P D_{i k}\right),\left(E P D_{j 1}-P D_{j l}\right)\right]$ is zero. Because bulls of interest for interbreed comparison are not bulls used at MARC, COV[B $B_{i j}$, $\left(\mathrm{EPD}_{\mathrm{ik}}-\mathrm{PD}_{\mathrm{ik}}\right)-$ $\left.\left(E P D_{j 1}-P D_{j 1}\right)\right]$ is assumed to be zero. Thus, PEV of an interbreed comparison is as follows: 


$$
\mathrm{V}\left(\mathrm{B}_{\mathrm{ij}}\right)+\left(2-\mathrm{r}_{\mathrm{ik}}^{2}-\mathrm{r}_{\mathrm{jl}}^{2}\right) \sigma_{\mathrm{s}}^{2}
$$

Approximations for $\mathrm{r}_{\mathrm{ik}}^{2}$ and $\mathrm{r}_{\mathrm{jl}}^{2}$ can be obtained from summaries of breed genetic evaluations. If estimated accuracy as recommended by the Beef Improvement Federation (Beef Improvement Federation, 1990) is reported $\left(r_{\mathrm{BIF}}\right)$, then $\mathrm{r}_{\mathrm{ik}}^{2}=1-\left(1-\mathrm{r}_{\mathrm{BIF}}\right)^{2}$, where the approximate prediction error variance (PEV) is used to calculate $\mathrm{r}_{\mathrm{BIF}}$ as $1-\left(\mathrm{PEV} / \sigma_{\mathrm{g}}^{2}\right) .5$ with $\sigma_{\mathrm{g}}^{2}$ the genetic variance for an animal model.

The part of the PEV that depends on MARC data is $V\left(B_{i j}\right)$. Despite the apparent simplicity of $B_{i j}=\left(L_{i}-\right.$ $\left.L_{j}\right)-\left(P_{i}-P_{j}\right)$, several options exist for calculating the terms and corresponding variances and covariances. For example, $\mathrm{L}_{\mathrm{i}}$ and $\mathrm{L}_{\mathrm{j}}$ can be the ordinary least squares estimates of sire breed effects from MARC data or can be mixed-model estimates if sires within breed are included in the model with variance of sire effects, $\sigma_{\mathrm{s}}^{2}$, equal for all breeds and variance of residual effects, $\sigma_{\mathrm{e}}^{2}$, equal for all breeds. If ordinary least squares is used, consideration of the contribution of random sire effects will give a sampling variance different from the apparent variance from ordinary least squares. Similarly, $P_{i}$ and $P_{j}$ may be either weighted or unweighted averages of EPD from breed associations for bulls used at MARC. In general

$$
\begin{aligned}
V\left(B_{i j}\right)= & V\left[\left(L_{i}-L_{j}\right)-\left(P_{i}-P_{j}\right)\right] \\
= & V\left(L_{i}\right)+\left(L_{j}\right)+V\left(P_{i}\right)+V\left(P_{j}\right) \\
& -2\left[\operatorname{COV}\left(L_{i}, P_{i}\right)+\operatorname{COV}\left(L_{j}, P_{j}\right)\right]
\end{aligned}
$$

with other terms approximated by zero for the stated assumptions. Let

$$
\begin{aligned}
\mathrm{n}_{\mathrm{i}}= & \text { number of bulls of breed } \mathrm{i} \text { used at MARC } \\
& \text { with breed association EPD, } \\
\mathrm{m}_{\mathrm{ik}}= & \text { number of progeny with a record at MARC } \\
& \text { for bull ik, } \\
\mathrm{N}_{\mathrm{i}}= & \sum_{\mathrm{k}} \mathrm{m}_{\mathrm{ik}}=\text { number of progeny of breed } \mathrm{i} \text { at } \\
& \text { MARC, } \\
\mathrm{r}_{\mathrm{ik}}^{2}= & \begin{array}{l}
\text { square of the approximation for correlation } \\
\text { of true and breed association EPD for bull }
\end{array} \\
& \mathrm{ik}, \\
\mathrm{y}_{\mathrm{ik}}= & \text { sum of records at MARC of progeny of bull } \\
& \mathrm{ik}, \text { and } \\
\lambda= & \sigma_{\mathrm{e}}^{2} / \sigma_{\mathrm{s}}^{2}, \text { a constant for all breeds. }
\end{aligned}
$$

If $\mathrm{P}_{\mathrm{i}}$ is the unweighted mean EPD for bulls of breed $\mathrm{i} ; \mathrm{V}\left(\mathrm{P}_{\mathrm{i}}\right)=\left(\sum_{\mathrm{k}} \mathrm{r}_{\mathrm{ik}}^{2} / \mathrm{n}_{\mathrm{i}}^{2}\right) \sigma_{\mathrm{s}}^{2}$ because $\mathrm{V}\left(\mathbf{P}_{\mathrm{ik}}\right)=\mathrm{r}_{\mathrm{ik}}^{2} \sigma_{\mathrm{s}}^{2}$ with the bulls assumed to be unrelated and is approximately true in most cases with related sires.
If $P_{i}$ is the weighted (by $m_{i k}$ ) mean EPD for bulls of breed i;

$$
\mathrm{V}\left(\mathrm{P}_{\mathrm{i}}\right)=\left[\left(\sum_{\mathrm{k}} \mathrm{m}_{\mathrm{ik}}^{2} \mathrm{r}_{\mathrm{ik}}^{2}\right) /\left(\mathrm{N}_{\mathrm{i}}\right)^{2}\right] \sigma_{\mathrm{s}}^{2} .
$$

If all $\mathrm{m}_{\mathrm{ik}}$ are equal and all $\mathrm{r}_{\mathrm{ik}}^{2}=\mathrm{r}_{\mathrm{i}}^{2}$, both expressions reduce to $\mathrm{V}\left(\mathrm{P}_{\mathrm{i}}\right)=\left(\mathrm{r}_{\mathrm{i}}^{2} / \mathrm{n}_{\mathrm{i}}\right) \sigma_{\mathrm{s}}^{2}$.

\section{Ordinary Least Squares}

\section{Estimates of Sire Breed Effects}

With a one-way fixed classification (sire breed) model, the ordinary least squares estimate (LSE) of the $i^{\text {th }}$ sire breed effect is as follows:

$$
\mathrm{L}_{\mathrm{i}}=\mathrm{y}_{\mathrm{i} \bullet} / \mathrm{N}_{\mathrm{i}} \text {. }
$$

The apparent $\mathrm{V}\left(\mathrm{L}_{\mathrm{i}}\right) \cong\left(\sigma_{\mathrm{s}}^{2}+\sigma_{\mathrm{e}}^{2}\right) / \mathrm{N}_{\mathrm{i}}$. But if sires within breed are random effects, the true variance is as follows:

$$
\mathrm{V}\left(\mathrm{L}_{\mathrm{i}}\right)=\left[\left(\sum_{\mathrm{k}} \mathrm{m}_{\mathrm{ik}}^{2}\right)\left(\mathrm{N}_{\mathrm{i}}^{2}\right)\right] \sigma_{\mathrm{s}}^{2}+\left(1 / \mathrm{N}_{\mathrm{i}}\right) \sigma_{\mathrm{e}}^{2} .
$$

Comparison of the apparent and actual variances of the least squares estimates suggests that ordinary least squares may substantially underestimate $\mathrm{V}\left(\mathrm{L}_{\mathrm{i}}\right)$ depending on ratio of $\sigma_{\mathrm{s}}^{2}: \sigma_{\mathrm{e}}^{2}$.

If $\mathrm{m}_{\mathrm{ij}}=\mathrm{m}$ for all bulls of breed $\mathrm{i}$;

$$
\mathrm{V}\left(\mathrm{L}_{\mathrm{i}}\right)=\left[(\mathrm{m}+\lambda) / \mathrm{N}_{\mathrm{i}}\right] \sigma_{\mathrm{s}}^{2} \text {. }
$$

If $P_{i}$ is unweighted;

$$
\operatorname{Cov}\left(L_{i}, P_{i}\right)=\left[\left(\sum_{k} m_{i k} r_{i k}^{2}\right) /\left(N_{i} n_{i}\right)\right] \sigma_{s}^{2}
$$

and if $m_{i k}=m$ and $r_{i k}^{2}=r_{i}^{2}$, then

$$
\operatorname{COV}\left(L_{i}, P_{i}\right)=\left(r_{i}^{2} / n_{i}\right) \sigma_{s}^{2}=V\left(P_{i}\right) .
$$

If $P_{i}$ is weighted by $m_{i k}$;

$$
\begin{aligned}
& \operatorname{COV}\left(\mathrm{L}_{\mathrm{i}}, \quad \mathrm{P}_{\mathrm{i}}\right)=\left[\left(\sum_{\mathrm{k}} \mathrm{m}_{\mathrm{ik}}^{2} \mathrm{r}_{\mathrm{ik}}^{2}\right) /\left(\mathrm{N}_{\mathrm{i}}^{2}\right)\right] \sigma_{\mathrm{s}}^{2} \\
& =\mathrm{V}\left(\mathrm{P}_{\mathrm{i}}\right)
\end{aligned}
$$

and if $\mathrm{m}_{\mathrm{ik}}=\mathrm{m}$ and $\mathrm{r}_{\mathrm{ik}}^{2}=\mathrm{r}_{i}^{2}$; then

$$
\operatorname{COV}\left(\mathrm{L}_{\mathrm{i}}, \mathrm{P}_{\mathrm{i}}\right)=\left(\mathrm{r}_{\mathrm{i}}^{2} / \mathrm{n}_{\mathrm{i}}\right) \sigma_{\mathrm{s}}^{2}=\mathrm{V}\left(\mathrm{P}_{\mathrm{i}}\right) \text {. }
$$

\section{Mixed-Model Estimates of Sire Breed Effects}

For a model with random sire effects nested within sire breeds, the mixed-model equations (MME) for sires can be absorbed into the sire breed equations. The equation for sire breed i becomes:

$$
\begin{aligned}
& \lambda\left\{\sum_{\mathrm{k}}\left[\mathrm{m}_{\mathrm{ik}} /\left(\mathrm{m}_{\mathrm{ik}}+\lambda\right)\right]\right\} \mathrm{b}_{\mathrm{i}} \\
& =\lambda\left\{\sum_{\mathrm{k}}\left[\mathrm{y}_{\mathrm{ik}} \mathrm{d}\left(\mathrm{m}_{\mathrm{ik}}+\lambda\right)\right]\right\}
\end{aligned}
$$


so that $b_{i}=$

$$
\sum_{k}\left[y_{i k d} /\left(m_{i k}+\lambda\right)\right] / \sum_{k}\left[m_{i k} /\left(m_{i k}+\lambda\right)\right]
$$

with $\mathrm{V}\left(\mathrm{b}_{\mathrm{i}}\right)=\sigma_{\mathrm{s}}^{2} / \sum_{\mathrm{k}}\left[\mathrm{m}_{\mathrm{ik}} /\left(\mathrm{m}_{\mathrm{ik}}+\lambda\right)\right]$.

$\mathrm{Ifm}_{\mathrm{ik}}=\mathrm{m}$ for all $\mathrm{ik}$,

$\mathrm{V}\left(\mathrm{b}_{\mathrm{i}}\right)=\sigma_{\mathrm{s}}^{2}\left[(\mathrm{~m}+\lambda) / \mathrm{N}_{\mathrm{i}}\right]=\mathrm{V}\left(\mathrm{L}_{\mathrm{i}}\right)$

If $P_{i}$ is unweighted;

$\operatorname{COV}\left(\mathrm{b}_{\mathrm{i}}, \mathrm{P}_{\mathrm{i}}\right)=\left[\left(\sum_{\mathrm{k}} \mathrm{c}_{\mathrm{ik}}^{2} \mathrm{r}_{\mathrm{ik}}^{2}\right)\left(\mathrm{n}_{\mathrm{i}} \sum_{\mathrm{k}} \mathrm{c}_{\mathrm{ik}}^{2}\right)\right] \sigma_{\mathrm{s}}^{2}$

where $c_{\mathrm{ik}}^{2}=\mathrm{m}_{\mathrm{ik}} /\left(\mathrm{m}_{\mathrm{ik}}+\lambda\right)$.

Then if $\mathrm{m}_{\mathrm{ik}}=\mathrm{m}$ and $\mathrm{r}_{\mathrm{ik}}^{2}=\mathrm{r}_{\mathrm{i}}^{2}$ for all ik,

$$
\operatorname{COV}\left(b_{i}, \quad P_{i}\right)=\left(r_{i}^{2} / n_{i}\right) \sigma_{s}^{2}=V\left(P_{i}\right)
$$

If $\mathrm{P}_{\mathrm{i}}$ is weighted (by $\mathrm{m}_{\mathrm{ik}}$ );

$$
\operatorname{COV}\left(b_{i}, P_{i}\right)=\left[\left(\sum_{k} m_{i k} c_{i k}^{2} r_{i k}^{2}\right)\left(N_{i} \sum_{k} c_{i k}^{2}\right)\right] \sigma_{s}^{2} .
$$

Then if $\mathrm{m}_{\mathrm{ik}}=\mathrm{m}$ and $\mathrm{r}_{\mathrm{ik}}^{2}=\mathrm{r}_{\mathrm{i}}^{2}$ for all ik,

$$
\operatorname{Cov}\left(\mathrm{b}_{\mathrm{i}}, \mathrm{P}_{\mathrm{i}}\right)=\left(\mathrm{r}_{\mathrm{i}}^{2} / \mathrm{n}_{\mathrm{i}}\right) \sigma_{\mathrm{s}}^{2}=\mathrm{V}\left(\mathrm{P}_{\mathrm{i}}\right)
$$

\section{Results and Discussion}

The approximate theoretical variances for $L_{i}, b_{i}, P_{i}$ and covariances of $L_{i}$ and $b_{i}$ with $P_{i}$ are given in Table 1. The columns for theoretical variances are based on a simple sires-within-breed model. The comparison of the LSE (O) and LSE ( S) columns shows substantial reductions in variance when the random effects of sires are ignored. As expected, the theoretical variances of the estimates from the MME are smaller than those for the least squares equations when the variances of the least squares solutions are calculated under the correct model. The following columns show the theoretical approximations of the variances of mean EPD of bulls used at MARC and covariances with least squares and mixed-model estimates of breed effects. The last column is $V\left(P_{i}\right)-2 \operatorname{COV}\left(P_{i}\right.$, $\left.b_{i}\right)$, which can be used in calculation of $V\left(B_{i j}\right)$.

In actual analyses the fixed part of the model includes more fixed factors than sire breeds. There- fore, the difference in sire breed solutions is the estimable function needed to adjust for breeds for interbreed EPD. Table 2 compares $\mathrm{V}\left(\mathrm{L}_{\mathrm{i}}-\mathrm{L}_{\mathrm{j}}\right)$, the apparent variance, of the breed contrasts from ordinary LSE and $V\left(b_{i}-b_{j}\right)$ the variance of the contrasts from MME for weaning weight for the MARC data. For example, the apparent variance of the contrast between breeds 1 and 2 from LSE is $2.73 \mathrm{~kg}^{2}$, but the variance of the contrast from MME is $6.49 \mathrm{~kg}^{2}$. The theoretical approximations (Table 1) are $(1.74+.84=$ $2.58) \mathrm{kg}^{2}$ and $(4.23+1.97=6.20) \mathrm{kg}^{2}$, which as expected are somewhat smaller than those from a model with additional fixed effects. When the contributions to the LSE breed contrast of random sires within breed are considered, the theoretical approximation to the variance of the LSE contrast is $(6.41+$ $2.57=8.98) \mathrm{kg}^{2}$, which illustrates the sizeable underestimation by ordinary LSE of the contrast variance when random sires within breeds are ignored. The exact variance would be difficult to obtain from the LSE analysis, although the contrast variance from LSE obviously would be considerably underestimated. The contrast variance from MME can be obtained relatively easily and, as expected, is slightly larger than the complete theoretical approximation.

\section{Variance of Adjusted Breed Difference}

A reasonable approach for calculating $\mathrm{PEV}$ for interbreed EPD would be to use $V\left(b_{i}-b_{j}\right)$ from MME with random sires nested within breed in calculating the variance of the breed difference adjusted for genetic trend and sire sampling, that is,

$$
\begin{aligned}
\mathrm{V}\left(\mathrm{B}_{\mathrm{ij}}\right)= & \mathrm{V}\left[\left(\mathrm{b}_{\mathrm{i}}-\mathrm{P}_{\mathrm{i}}\right)-\left(\mathrm{b}_{\mathrm{j}}-\mathrm{P}_{\mathrm{j}}\right)\right]=\mathrm{V}\left[\left(\mathrm{b}_{\mathrm{i}}-\mathrm{b}_{\mathrm{j}}\right)\right. \\
& \left.-\left(\mathrm{P}_{\mathrm{i}}-\mathrm{P}_{\mathrm{j}}\right)\right] .
\end{aligned}
$$

With assumptions listed earlier

$$
\begin{aligned}
V\left(B_{i j}\right)= & V\left(b_{i}-b_{j}\right)+V\left(P_{i}\right)-2 \operatorname{COV}\left(b_{i}, P_{i}\right) \\
& +V\left(P_{j}\right)-2 \operatorname{COV}\left(b_{j}, P_{j}\right)
\end{aligned}
$$

where $P_{i}$ and $P_{j}$ are the weighted means of breed association EPD of bulls with progeny in the MARC analysis. The $\mathrm{V}\left(\mathrm{P}_{\mathrm{j}}\right)$ and $\operatorname{COV}\left(\mathrm{b}_{\mathrm{i}}, \mathrm{P}_{\mathrm{i}}\right)$ terms would need to be approximated by formulas given earlier and for this analysis are shown in Table 1 , where the last column gives the quantities to subtract from $V\left(b_{i}-b_{j}\right)$ to give $\mathrm{V}\left(\mathrm{B}_{\mathrm{ij}}\right)$.

For example, for interbreed comparison of bulls of breeds 1 and 3 ,

$$
\begin{aligned}
V\left(B_{13}\right)= & V\left(b_{1}-b_{3}\right)+V\left(P_{1}\right)-2 \operatorname{CoV}\left(b_{1}, P_{1}\right) \\
& +V\left(P_{3}\right)-2 \operatorname{COV}\left(b_{3}, P_{3}\right)
\end{aligned}
$$

where $b_{k}$ is the MME solution for breed $k, V\left(P_{k}\right)$ is the approximate theoretical variance of weighted mean EPD of bulls used at MARC of breed $k$, and $\operatorname{COV}\left(b_{k}, P_{k}\right)$ is the approximate theoretical covariance between $b_{k}$ and $P_{k}$. For the MARC analysis of weaning weight: 
Table 1. Theoretical approximations by breed for the variances of least squares estimates $\left(\mathrm{L}_{\mathrm{i}}\right)$ of breed of sire effects [LSE $(\mathrm{O})$ for ignoring sires, $\mathrm{LSE}(\mathrm{S})$ for considering effects of random sires] for mixed-model estimates (MME) of breed effects $\left(b_{i}\right)$, for the variance of mean $\left(P_{i}\right)$ of breed EPD (unweighted and weighted by number of progeny at MARC), for covariances $(C O V)$ of $\mathrm{L}_{i}$ and $\mathrm{P}_{\mathbf{i}}$ and of $\mathrm{b}_{\mathbf{i}}$ and $\mathrm{P}_{\mathrm{i}}$, and factor to adjust variance of mixed-model breed contrasts for genetic trend-weaning weight $(\mathrm{kg})$ with

$$
\sigma_{\mathrm{s}}^{2}=39.36 \mathrm{~kg}^{2} \text { and } \sigma_{\mathrm{e}}^{2}=503.47 \mathrm{~kg}^{2}
$$

\begin{tabular}{|c|c|c|c|c|c|c|c|c|c|c|c|c|}
\hline \multirow[b]{3}{*}{ Breed } & \multirow{2}{*}{\multicolumn{2}{|c|}{ No. }} & \multirow{2}{*}{\multicolumn{3}{|c|}{ Theoretical variances }} & \multirow{2}{*}{\multicolumn{2}{|c|}{ Variance $\left(\mathrm{P}_{\mathrm{i}}\right)$}} & \multicolumn{4}{|c|}{$-2 \operatorname{Cov}\left(P_{i}, L_{i}\right.$, or $\left.b_{i}\right)$} & \multirow{3}{*}{$\begin{array}{c}\text { Adjust } \\
\text { MME } \\
\text { contrast }^{\mathrm{d}}\end{array}$} \\
\hline & & & & & & & & \multicolumn{2}{|c|}{$\left(\mathrm{P}_{\mathrm{i}}, \mathrm{L}_{\mathrm{i}}\right)$} & \multicolumn{2}{|c|}{$\left(P_{i}, b_{i}\right)$} & \\
\hline & Sires & Progeny & $\operatorname{LSE}(O)^{a}$ & $\operatorname{LSE}(S)^{b}$ & MME & Unwtd. & Wtd. & Unwtd. & Wtd. & Unwtd. & Wtd. & \\
\hline 1 & 28 & 311 & 1.74 & 6.41 & 4.23 & 1.23 & 3.11 & -2.10 & -6.22 & -2.34 & -3.62 & -.51 \\
\hline 2 & 36 & 548 & .99 & 3.40 & 2.57 & .89 & 1.97 & -1.72 & -3.93 & -1.73 & -2.59 & -.62 \\
\hline 3 & 61 & 646 & .84 & 2.57 & 1.97 & .51 & 1.09 & -.85 & -2.18 & -.92 & -1.48 & -.39 \\
\hline $4^{c}$ & 25 & 170 & 3.19 & 4.84 & 4.76 & - & - & - & - & - & - & - \\
\hline 5 & 20 & 186 & 2.92 & 6.03 & 5.46 & 1.48 & 2.67 & -3.09 & -5.34 & -3.03 & -4.39 & -1.72 \\
\hline 6 & 27 & 366 & 1.48 & 3.68 & 3.25 & 1.45 & 2.30 & -2.91 & -4.60 & -2.90 & -3.74 & -1.44 \\
\hline 7 & 20 & 338 & 1.61 & 4.47 & 3.89 & 1.95 & 2.97 & -3.92 & -5.95 & -3.91 & -4.78 & -1.81 \\
\hline 8 & 57 & 472 & 1.15 & 2.23 & 2.03 & .51 & .90 & -1.00 & -1.80 & -.98 & -1.42 & -.51 \\
\hline 9 & 15 & 155 & 3.50 & 5.99 & 5.94 & 1.38 & 1.48 & -2.80 & -2.96 & -2.78 & -2.89 & -1.41 \\
\hline 10 & 25 & 355 & 1.53 & 3.59 & 3.25 & .97 & 1.70 & -2.20 & -3.40 & -2.05 & -2.70 & -1.00 \\
\hline 11 & 11 & 376 & 1.44 & 5.58 & 5.23 & 2.85 & 3.54 & -5.90 & -7.09 & -5.80 & -6.46 & -2.92 \\
\hline 12 & 27 & 176 & 3.08 & 4.64 & 4.55 & 1.33 & 1.64 & -2.68 & -3.29 & -2.68 & -3.11 & -1.47 \\
\hline
\end{tabular}

apparent variance because variation among sires is ignored.

${ }^{b}$ Variance of least squares estimate after considering variation among sires.

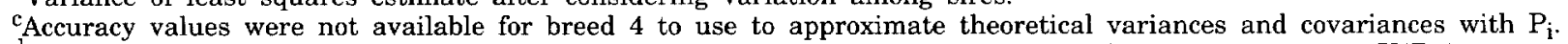

${ }^{d} \mathrm{~V}\left(P_{j}\right)-2 \operatorname{COV}\left(P_{i}, b_{i}\right)$ and $V\left(P_{j}\right)-2 \operatorname{COV}\left(P_{j}, b_{j}\right)$ are added to $V\left(b_{i}-b_{j}\right)$ in Table 2 to approximate $V\left(B_{i j}\right)$.

$$
\begin{aligned}
\mathrm{V}\left(\mathrm{B}_{13}\right)= & {[6.49+(3.110-3.616)} \\
& +(1.092-1.484)] \mathrm{kg}^{2}=5.59 \mathrm{~kg}^{2} .
\end{aligned}
$$

The theoretical approximation would be $[6.20-.51$

$$
-.39 \mathrm{~kg}^{2}=5.30 \mathrm{~kg}^{2} \text {. }
$$

\section{Variance of Prediction Error}

The next question is whether $\mathrm{V}\left(\mathrm{B}_{\mathrm{ij}}\right)$ is an important part of

$$
\begin{gathered}
\mathrm{V}\left[\left(\hat{\mathbf{u}}_{\mathrm{ik}}-\hat{\mathrm{u}}_{\mathrm{jl}}\right)-\left(\mathbf{u}_{\mathrm{ik}}-\mathrm{u}_{\mathrm{jl}}\right)\right]=\mathrm{V}\left(\mathrm{B}_{\mathrm{ij}}\right) \\
+\left(2-\mathrm{r}_{\mathrm{ik}}^{2}-\mathrm{r}_{\mathrm{jl}}^{2}\right) \sigma_{\mathrm{s}}^{2} .
\end{gathered}
$$

From Tables 1 and 2 using the variances for contrasts based on the MME, one of the largest $\mathrm{V}\left(\mathrm{B}_{\mathrm{ij}}\right)$ is $\mathrm{V}\left(\mathrm{B}_{59}\right)=[15.53-1.72-1.42=12.39] \mathrm{kg}^{2}$ and one of the smallest is $\mathrm{V}\left(\mathrm{B}_{38}\right)=[4.40-.39-.51=3.50] \mathrm{kg}^{2}$. The relative importance of $\mathrm{V}\left(\mathrm{B}_{\mathrm{ij}}\right)$ in PEV can be seen by calculating $\mathrm{PEV}=\mathrm{V}\left(\mathrm{B}_{\mathrm{ij}}\right)+\left(2-\mathrm{r}_{\mathrm{ik}}^{2}-\mathrm{r}_{\mathrm{jl}}^{2}\right) \sigma_{\mathrm{s}}^{2}$ for various $r_{\mathrm{ik}}^{2}$ and $\mathrm{r}_{\mathrm{j} \text {. }}^{2}$ Note that $\mathrm{V}\left(\mathrm{B}_{\mathrm{ii}}\right)=0$. Table 3 shows standard errors of prediction, SEP $=(\mathrm{PEV})^{.5}$, for various $\mathrm{r}_{\mathrm{ik}}^{2}$ and $\mathrm{r}_{\mathrm{jl}}^{2}$ for $\mathrm{V}\left(\mathrm{B}_{\mathrm{ii}}\right)=0, \mathrm{~V}\left(\mathrm{~B}_{38}\right)=3.50 \mathrm{~kg}^{2}$, $\mathrm{V}\left(\mathrm{B}_{59}\right)=12.39 \mathrm{~kg}^{2}$, and $\sigma_{\mathrm{s}}^{2}=39.36 \mathrm{~kg}^{2}$.

Table 3 shows that $\mathrm{V}\left(\mathrm{B}_{\mathrm{ij}}\right)$ does not make a very large contribution to the standard error of prediction even with the largest $V\left(B_{i j}\right)$. Except when $r_{i k}^{2}$ and $r_{j 1}^{2}$ are near unity, the proportional contribution of $\mathrm{V}\left(\mathrm{B}_{\mathrm{ij}}\right)$ to SEP is minor. The difference in SEP for two bulls of the same breed and two bulls of different breeds would be slight.
Another proposal has been to standardize interbreed comparisons to a standard breed, for example, breed 3 . The breed adjustment to common breed 3 and base year is a vector with elements:

$$
A_{i}=B_{i 3} .
$$

The interbreed EPD for bull $k$ of breed $i$ would be:

$$
A_{i}+E D_{i k}
$$

This adjustment is to the basis of the average of animals of breed 3 born in the base year. The corresponding $\mathrm{PEV}$ is as follows:

$$
\mathrm{V}\left(\mathrm{A}_{\mathrm{i}}\right)+\left(1-\mathrm{r}_{\mathrm{ik}}^{2}\right) \sigma_{\mathrm{s}}^{2}
$$

where $V\left(A_{i}\right)=V\left(B_{i 3}\right)$. Again, note that the withinbreed-3 evaluation is

$$
\begin{aligned}
\mathrm{A}_{3}+\mathrm{EPD}_{3 \mathrm{k}} & =0+\mathrm{EPD}_{3 \mathrm{k}} \text { with } \mathrm{V}\left(\mathrm{A}_{3}\right) \\
& =\mathrm{V}\left(\mathrm{B}_{33}\right)=0
\end{aligned}
$$

Table 4 shows SEP $=\left[\mathrm{V}\left(\mathrm{A}_{\mathrm{i}}\right)+\left(1-\mathrm{r}_{\mathrm{ik}}^{2}\right) \sigma_{\mathrm{s}}^{2}\right]^{5}$ for four breeds, including the base breed 3 , and varying $r_{\mathrm{ik}}^{2}$ for weaning weight.

Only for accuracy near unity is the difference between SEP for a bull of the base breed and SEP for a bull of another breed very noticeable. The SEP when within-breed accuracy is unity is the square root of the variance of the difference between the breed constants 
Table 2. Solutions for breed of sire and apparent variances of all pairwise contrasts for breed of sire effects from ordinary least squares (LSE) analysis ignoring sires within breed of sire (above diagonal) and from mixed-model equations (MME) with sires nested within breed of sire (below diagonal) for weaning weight $(\mathrm{kg})$ with $\sigma_{\mathrm{s}}^{2}=39.36 \mathrm{~kg}^{2}$ and $\sigma_{\mathrm{e}}^{2}=503.47 \mathrm{~kg}^{2}$

\begin{tabular}{|c|c|c|c|c|c|c|c|c|c|c|c|c|}
\hline Breed & 1 & 2 & 3 & 4 & 5 & 6 & 7 & 8 & 9 & 10 & 11 & 12 \\
\hline \multicolumn{13}{|l|}{ Breed } \\
\hline 1 & - & 2.94 & 2.73 & 5.60 & 5.65 & 4.65 & 4.72 & 3.56 & 6.95 & 4.11 & 4.47 & 5.42 \\
\hline 2 & 7.46 & - & 1.89 & 4.79 & 5.43 & 3.49 & 3.54 & 2.50 & 5.86 & 3.02 & 3.88 & 4.62 \\
\hline 3 & 6.49 & 4.69 & - & 4.56 & 5.27 & 3.44 & 3.50 & 2.42 & 5.67 & 2.90 & 3.84 & 4.40 \\
\hline 4 & 9.92 & 7.96 & 7.23 & - & 8.82 & 6.75 & 6.90 & 5.34 & 9.09 & 5.89 & 7.20 & 6.36 \\
\hline 5 & 10.64 & 10.30 & 9.18 & 13.38 & - & 7.54 & 7.56 & 6.50 & 9.82 & 6.89 & 5.00 & 8.67 \\
\hline 6 & 9.58 & 6.98 & 6.65 & 10.56 & 12.68 & - & 3.22 & 2.88 & 8.03 & 5.06 & 6.11 & 6.60 \\
\hline 7 & 10.20 & 7.54 & 7.23 & 11.20 & 13.25 & 7.22 & - & 3.02 & 8.06 & 5.05 & 6.16 & 6.76 \\
\hline 8 & 7.26 & 4.83 & 4.40 & 7.72 & 10.43 & 5.76 & 6.40 & - & 6.93 & 3.84 & 5.04 & 5.19 \\
\hline 9 & 12.66 & 10.52 & 9.83 & 13.56 & 15.53 & 12.84 & 13.42 & 10.62 & - & 5.57 & 8.41 & 8.95 \\
\hline 10 & 8.75 & 6.43 & 5.91 & 9.15 & 11.63 & 8.92 & 9.44 & 6.40 & 10.05 & - & 5.50 & 5.80 \\
\hline 11 & 11.33 & 9.55 & 8.90 & 12.53 & 12.29 & 11.95 & 12.54 & 9.67 & 14.64 & 10.84 & - & 7.04 \\
\hline 12 & 9.63 & 7.68 & 6.97 & 9.41 & 13.13 & 10.30 & 10.95 & 7.48 & 13.31 & 8.96 & 12.27 & - \\
\hline \multicolumn{13}{|c|}{ Solutions } \\
\hline MME & 8.52 & -.57 & .00 & 12.09 & 9.04 & 11.93 & 6.36 & 13.96 & 13.73 & 13.98 & 1.03 & 14.14 \\
\hline LSE & 3.46 & -.12 & .00 & 12.79 & 9.97 & 12.73 & 7.26 & 14.56 & 14.43 & 15.56 & 3.38 & 15.71 \\
\hline
\end{tabular}

estimated from MARC data after adjustment to a common base year and genetic trend.

If regressions of progeny performance on withinbreed sire EPD are not assumed to be unity, the procedures discussed here would need to be modified. The steps that would be needed would be 1) to use the mixed-model method to estimate breed contrasts from MARC records, 2) to use least squares to estimate the within-breed regression of progeny records on sire EPD, 3) to use the Notter-Cundiff (1991) method to adjust for genetic trend, and 4) to modify the expressions given for finding the variances of the adjusted breed contrasts.

Table 3. Standard errors of prediction a of progeny differences for inter-and within-breed comparisons ${ }^{b}$ for various accuracies $\left(r_{i k}^{2}, r_{j l}^{2}\right)$ between pairs of bulls for weaning weight $(\mathrm{kg})$

\begin{tabular}{ccccc}
\hline \hline $\mathrm{r}_{\mathrm{ik}}^{2}$ & $\mathrm{r}_{\mathrm{jl}}^{2}$ & $\begin{array}{c}\mathrm{V}\left(\mathrm{B}_{\mathrm{ji}}\right) \\
=\mathbf{0}^{\mathrm{b}}\end{array}$ & $\begin{array}{c}\mathrm{V}\left(\mathrm{B}_{38}\right) \\
=3.50^{\mathrm{c}}\end{array}$ & $\begin{array}{c}\mathrm{V}\left(\mathrm{B}_{\mathbf{5 9}}\right) \\
=12.39^{\mathrm{d}}\end{array}$ \\
\hline 1.0 & 1.0 & .00 & 1.87 & 3.52 \\
.75 & .75 & 4.44 & 4.81 & 5.66 \\
.50 & .50 & 6.27 & 6.55 & 7.19 \\
.25 & .25 & 7.68 & 7.91 & 8.45 \\
.00 & .00 & 8.87 & 9.07 & 9.55 \\
\hline
\end{tabular}

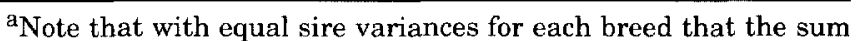
of $r_{\mathrm{jk}}^{2}$ and $r_{\mathrm{j} l}^{2}$ determines SEP; e.g., .75 and .75 is equivalent to 1.00 and .50 .

${ }^{\mathrm{b}} \mathrm{B}_{\mathrm{ii}}$ is within-breed adjustment with variance, $\mathrm{V}\left(\mathrm{B}_{\mathrm{ii}}\right)$

${ }^{c} B_{38}$ is estimated constant for difference between breeds 3 and 8 with variance, $\mathrm{V}\left(\mathrm{B}_{38}\right)$.

${ }^{d_{B}} B_{59}$ is estimated constant for difference between breeds 5 and 9 with variance, $\mathrm{V}\left(\mathrm{B}_{59}\right)$.

\section{Conclusions}

Breed constants used for constructing breed adjustments for interbreed EPD should be estimated using a mixed model to consider variation due to sires within breeds. The variances of such breed contrasts are larger and more nearly correct than variances of contrasts based on least squares estimates ignoring sire variation within breeds. For predicting progeny difference between pairs of bulls, differences in variances of breed adjustments have little effect on standard error of prediction of the difference between progeny of pairs of bulls with perhaps a noticeable effect when within-breed accuracy is near unity. Prediction of progeny difference between pairs of bulls emphasizes the principle that only differences in breeding values or progeny differences can be predicted. Standard errors of prediction for such differences can be readily approximated from contrast variances of the MARC analyses and from theoretical approximations for the variances of the adjustments for genetic trend and the covariances between the adjustments for genetic trend and the MARC constants. Both prediction of progeny difference between pairs of bulls adjusted for breed differences and the alternative of adjusting to a constant breed and year basis require using SEP rather than accuracy as a measure of reliability. A way to express reliability of interbreed EPD on an accuracy scale is not obvious. Thus, explanation of the use of SEP in constructing confidence ranges would be needed.

Several simplifying assumptions were made in this discussion that are likely not to be exactly fulfilled. Testing whether different breed crosses have different variances in the reference environments is difficult. The portion of the PEV associated with the analyses in 
Table 4. Standard errors of prediction for bulls of four breeds for prediction equal to adjustment to basis of breed 3 plus the within-breed EPD for weaning weight $(\mathrm{kg})$ with $\sigma_{\mathrm{s}}^{2}=39.36 \mathrm{~kg}^{2}$ and $\sigma_{\mathrm{e}}^{2}=503.47 \mathrm{~kg}^{2}$

\begin{tabular}{lcccccc}
\hline \hline & & \multicolumn{5}{c}{$\mathrm{r}^{2}$} \\
\cline { 3 - 7 } Breed = i & $\mathrm{V}\left(\mathrm{A}_{\mathbf{i}}\right)^{\mathrm{a}}$ & 1.0 & .75 & .50 & .25 & .00 \\
\hline 3 & .00 & 0 & 3.14 & 4.44 & 5.43 & 6.27 \\
5 & 9.18 & 3.03 & 4.36 & 5.37 & 6.22 & 6.97 \\
8 & 4.40 & 2.10 & 3.77 & 4.91 & 5.82 & 6.62 \\
9 & 9.83 & 3.14 & 4.44 & 5.43 & 6.27 & 7.01 \\
\hline
\end{tabular}

${ }^{a} \mathrm{~V}\left(\mathrm{~A}_{\mathbf{i}}\right)$ is variance of estimate of constant for difference between breed 3 and breed $i$.

reference environments, however, is not generally of much importance, so different variances for different breeds may not be very important for estimating the sire breed difference. The portion of PEV associated with the within-breed EPD of individual sires easily can be adjusted to use different variances for different breeds, although the effect of the dam breed on that variance may need to be considered. The assumption of a unit regression of progeny performance on sire EPD simplifies the algebra and, unless greatly different from unity, will have rather small effects on PEV.

\section{Implications}

The approach of calculating expected progeny difference for pairs of bulls would require extensive educational effort to explain such differences and their standard errors of prediction. A table of variances of breed contrasts would be needed to calculate standard error of prediction to go with a list of estimated breed differences adjusted for genetic trend. The alternative of adding to the within-breed expected progeny difference an adjustment to a base breed basis is not much different from what breeders now are provided. With this alternative only a list of variances of breed differences from the base breed would be needed to calculate standard errors of prediction. Differences in standard errors of prediction for bulls of the base breed and bulls of other breeds would make the apparent confidence ranges for bulls of the base breed seem smaller than those for other breeds. Selection, however, should not be on the basis of standard error of prediction but should be based on the prediction of progeny difference.

\section{Literature Cited}

Beef Improvement Federation. 1990. Guidelines for uniform improvement programs. University of Georgia, Athens.

Cundiff, L. V. 1993. Breed comparisons adjusted to a 1991 basis using current EPD. Proc. Beef Improvement Federation Res. Symp. and 25th Annu. Mtg. Asheville, NC.

Notter, D. R. 1989. EPD's for use across breeds. Proc. Beef Improvement Federation Res. Symp. and 21st Annu. Mtg. Nashville, TN.

Notter, D. R., and L. V. Cundiff. 1991. Across-breed expected progeny differences: Use of within-breed expected progeny differences to adjust breed evaluations for sire sampling and genetic trend. J. Anim. Sci. 69:4763.

Núñez-Dominguez, R., L. V. Cundiff, and L, D. Van Vleck, 1992. Breed comparisons adjusted for within breed genetic trends using EPD's. Proc. Beef Improvement Federation Res. Symp. and 24th Annu. Mtg. Portland, OR.

Núñez-Dominguez, R., L. D. Van Vleck, and L. V. Cundiff. 1993. Breed comparisons for growth traits adjusted for within-breed genetic trend using expected progeny differences. J. Anim. Sci. 71:1419. 